\title{
Reliability of ultrasonographic measurements of bovine sole structures in relation to sole horn thickness, measured by computed tomography, and sole horn hardness
}

\author{
T. Tsuka, ${ }^{*}$ R. Nishimura, M. Hishinuma, Y. Murahata, M. Yamashita, K. Azuma, T. Osaki, N. Ito, Y. Okamoto, \\ and T. Imagawa \\ Department of Veterinary Clinical Medicine, School of Veterinary Medicine, Faculty of Agriculture, Tottori University, 4-101 Koyama-Minami, \\ Tottori, Japan, 680-8550
}

\section{ABSTRACT}

The goal of the present study was to determine the effect of sole horn thickness (SHT) and sole horn hardness (SHD) on ultrasonographic visualization of sole structures in the inner and outer claws of 150 HolsteinFriesian cows, and to evaluate different ultrasound frequencies for this purpose. Ultrasonographic views of the sole structure were considered complete when 3 echogenic lines, representing the ventral surface of the sole horn, the borders of the sole horn and soft-tissue layer, and the ventral surface of the distal phalanx, were seen. The proportion of complete ultrasonographic views of the sole structures, designated as the ultrasonographic visualization proportion (UVP), and the measurement errors of SHT were evaluated by comparing images from computed tomography (CT) and ultrasonography. The latter images were generated using 3 different probes, frequencies of 6.5 and $5.0 \mathrm{MHz}$, and 2 different ultrasound machines (\#1 and \#2) to assess the apex, middle, and heel regions of the claws. The UVP were 60.8 to $77.9 \%$ for the $6.5-\mathrm{MHz}$ probe in ultrasound machine \#1 (probe A), which were lower than those $(>90 \%)$ for both the $5.0-\mathrm{MHz}$ probe in ultrasound machine \#1 (probe $\mathrm{B}$ ) and the $5.0-\mathrm{MHz}$ probe in ultrasound machine \#2 (probe C). The UVP was significantly lower in claws with an SHD $\geq 50$ units than in claws with an SHD $<40$ or 40 to $<50$ units (UVP: $77.1 \%$ compared with 93.7 and $91.4 \%$, respectively) when measured with probe B. In claws with an SHT $<10 \mathrm{~mm}$, the UVP was significantly lower when SHD was $\geq 50$ units compared with $<40$ or 40 to $>50$ units; the values were $69.0 \%$ versus 91.3 and $85.9 \%$, respectively, for probe $\mathrm{A}$, and $89.7 \%$ versus 100 and $100 \%$, respectively, for probe B.

Received June 8, 2018.

Accepted June 3, 2019.

*Corresponding author: tsuka@muses.tottori-u.ac.jp
When SHT were measured by either probes A or B in ultrasound machine \#1, the proportions of claws in which ultrasonographic values were within a $\pm 1 \mathrm{~mm}$ range compared with the values obtained by $\mathrm{CT}$ were 84.9 to $91.3 \%$ for CT-determined SHT $<5 \mathrm{~mm}, 66.7$ to $71.9 \%$ for CT-determined SHT 5 to $<7 \mathrm{~mm}, 28.9$ to $51.2 \%$ for CT-determined SHT 7 to $<10 \mathrm{~mm}$, and 6.2 to $19.7 \%$ for CT-determined SHT $\geq 10 \mathrm{~mm}$. The data indicated that increased SHT was associated with a decrease in ultrasonographic measurement accuracy. In claws with an SHT $<5 \mathrm{~mm}$, the high proportion of ultrasonographic values that were accurate within a \pm 1 $\mathrm{mm}$ range suggests that this imaging modality would be useful in cows with thin soles.

Key words: bovine claw, computed tomography, sole horn thickness, ultrasonography

\section{INTRODUCTION}

In cattle, the sole horn needs to be of optimal hardness and thickness to maintain its protective function, and to resist mechanical stress, while allowing perception of stimuli, such as slippery, wet, and uneven surfaces and infection (Toussaint Raven, 1989). A sole horn thickness (SHT) of $7 \mathrm{~mm}$ is considered adequate in bovine claws, although this theory has never been tested scientifically (Toussaint Raven, 1989; Laven et al., 2012). Thicker sole horn is commonly associated with claw overgrowth, which occurs primarily at the apical region of the claw when foot trimming is not done regularly (Shearer and van Amstel, 2001). Overgrown claw horn may lead to unsteady gait and excessive weight-bearing on the flexor tuberosity, resulting in injury to the corium within the horn capsule and sole ulceration (Tsuka et al., 2014). Thin sole is an abnormal condition associated with an SHT of $<5 \mathrm{~mm}$, which may lead to bruising of the corium (Kofler et al., 1999; van Amstel et al., 2003, 2004; Laven et al., 2012). Compression of the sole horn manually or with hoof testers is a simple and common method used to 
estimate decreased SHT, based on palpable elasticity, which is suggestive of thin sole (van Amstel et al., 2003; Laven et al., 2012). However, this is a subjective technique for determining SHT because palpable elasticity is not a common feature of thin soles, and is not well suited for monitoring this condition (van Amstel et al., 2003). Therefore, measurement of SHT would be useful for evaluating claw condition and predicting potential problems.

Ultrasonography (US) of bovine claws has been reported to be the most objective technique to visualize and measure hoof structures (Laven et al., 2012). However, factors such as increased SHT, uneven sole surface, and sole horn hardness (SHD) affect the usefulness of US (Kofler et al., 1999; van Amstel et al., 2003), and thus errors in measurement of SHT may limit the application of US to bovine claws. A detailed quantitative assessment of SHT (measured with US) and SHD has not been previously undertaken. The correlation coefficient between US and anatomical measurements of SHT was approximately $\mathrm{r}=0.9$, although lower values of $\mathrm{r}=0.51$ to 0.64 were reported for the thickness of the underlying soft-tissue layer (Kofler et al., 1999). Compared with other anatomical structures of the bovine claw, SHT was frequently underestimated in claws with an SHT of $>5 \mathrm{~mm}$ using US (Kofler et al., 1999). However, these errors have not been investigated quantitatively.

Computed tomography (CT) has been used for quantitative evaluation of bovine claw structures (Kofler et al., 1999; Tsuka et al., 2014), and provides basic axial 2-dimensional (2-D) images. Reconstruction of 2-D images to the level of the mid-sagittal region is the most useful method for measurement of SHT (Kofler et al., 1999; Tsuka et al., 2014). A strong correlation ( $\mathrm{r}=$ 0.97-0.98) was observed between macroscopic and CT measurement of SHT (Tsuka et al., 2014).

The main aims of this study were to determine the usefulness of US for visualization of sole structures in bovine claws regardless of SHT and SHD, and to evaluate the accuracy of US measurements of claw structures regardless of SHT.

\section{MATERIALS AND METHODS}

A total of 300 inner and outer claws from 150 pairs of hind limbs of culled lactating Holstein-Friesian cows were obtained from a slaughterhouse (Tottori Meat Inspection Center, Tottori Prefectural Government, Tottori, Japan) between August 2011 and September 2016 (Table 1). The claws were free of sole disease including sole ulcer and white line disease, and the limbs had been amputated at the tarsometatarsal joint. The causes of culling included orthopedic disease (such as hip dislocation, and downer cow syndrome; $\mathrm{n}=79$ ), mastitis $(\mathrm{n}=27)$, abdominal disease (such as hepatitis, peritonitis, and enteritis; $\mathrm{n}=14$ ), displaced abomasum $(\mathrm{n}=11)$, respiratory disease $(\mathrm{n}=5)$, neurologic disease $(\mathrm{n}=4)$, and unknown reasons $(\mathrm{n}=10)$. The age of the cows ranged from 23 to $143 \mathrm{mo}$, and of the 150 cows, 131 were housed in 30 freestall or free-barn units $(\mathrm{n}=67)$ and 39 tiestall barns $(\mathrm{n}=64)$, and the housing type for the remaining 19 cows was unknown. All claws underwent minimal trimming before CT and US to smooth irregular sole surfaces. Trimming was minimized to maintain the original hoof shape. The study design included comparison between the values obtained by US and $\mathrm{CT}$ in bovine claws with variations in hoof shape and toe length (i.e., thin soles and overgrown horn). In addition, the data were assessed by comparing visualization performances of the 3 probes in 2 US machines, and the association with the SHD during particular sampling periods (Table 1). For all claws, US and CT were conducted on the same day they were obtained from the slaughterhouse.

\section{US Imaging Procedures}

The US examinations were carried out using 2 machines: machine \#1 (HI VISION Preirus, Hitachi-Aloka Medical, Tokyo, Japan) was used for all 150 pairs of hind limbs between August 2011 and September 2016 (Table 1). The probes included a $6.5-\mathrm{MHz}$ linear (probe A) and a $5.0-\mathrm{MHz}$ convex (probe B) types. The measurement accuracy of the probes was $0.1 \mathrm{~mm}$. Ultrasound machine \#2, a portable unit (HS-101V, Honda Electronics, Aichi, Japan), was used for 113 pairs of hind limbs between October 2012 and September 2016 (Table 1). The probe for that machine was a $5.0-\mathrm{MHz}$ linear type (probe C). Transmission gel was applied to the contact surface of the probe, which was subsequently used to scan the weight-bearing surface along imaginary longitudinal straight lines extending from the midpoint of the toe area to the middle of the heel (= palmar/plantar) area of the claws (Kofler et al., 1999). Of the 150 hind-limb pairs, the 113 were examined using 3 different probe to determine whether different wave frequencies (5.0 vs. $6.5 \mathrm{MHz}$ ) have an effect on visualization of the sole structures (Table 1). All 150 pairs of hind limbs were examined using US machine \#1 (probes A and B), and SHT measurements were obtained (Table 1 ).

\section{CT Imaging Procedures}

All 150 pairs of hind limbs were examined using CT between August 2011 and September 2016 (Table 1). The CT images were obtained using either a slip-ring 
scanner (Pronto SE, Hitachi, Tokyo, Japan) with X-ray tube settings of 100 or $120 \mathrm{kVp}$ and $100 \mathrm{~mA}$ and 2.5 mm slice thickness or a 16 -section multidetector scanner (ECLOS, Hitachi) with X-ray tube settings of 120 $\mathrm{kVp}$ and $175 \mathrm{~mA}$ and a $0.625-\mathrm{mm}$ slice thickness. Sagittal 2-D images were obtained using an image analysis system (AZE Virtual Place, AZE Corp., Tokyo, Japan).

\section{Quantitative Evaluations of CT and US Images}

Observations and quantitative evaluations of sole structures were done using longitudinal US images and basic sagittal 2-D CT images. The latter were reconstructed using the following process: (1) a mid-sagittal 2-D CT section of the claws was made, (2) the lines for transverse 2-D CT sections were drawn on the mid-sagittal section between a point at the apex of the distal phalanx and a point on the flexor tuberosity, and (3) on both transverse sections, a point at the center of the ventral surface of the sole horn was selected to draw the line to reconstruct the basic sagittal 2-D CT section. The US and CT measurements of SHT were taken at 3 points: sole 1 (S1), located on virtual lines between the most apical margin of the distal phalanx and the sole surface; sole 2 (S2), located on virtual lines between the deepest concavity of the ventral surface of the distal phalanx and the sole surface; and sole 3 (S3), located on virtual lines between the flexor tuberosity and the sole surface (Kofler et al., 1999; Tsuka et al., 2014; Figure 1). On the US images of bovine claws, sole structures were represented by 3 echogenic lines: a line at the ventral surface of the sole horn, a line that represented the borders of the sole horn and soft-tissue layer (S-S line), and a line at the ventral surface of the distal phalanx (DP line). When all 3 echogenic lines were seen in an image, this was defined as a complete US view. In addition, the proportion of sole structures visualized by US (UVP) was calculated by determining the proportion of claws with complete US views in the total number of claws examined by US.

\section{Measurements of SHD}

From August 2013 to September 2016, SHD was determined using a durometer (Type D; ESD model, Elastron, Kyoto, Japan). Measurements were taken at

Table 1. Numbers of claws used for examinations and statistical analyses

\begin{tabular}{|c|c|c|}
\hline Item & No. of claws & $\begin{array}{l}\text { Examination period and information from the examinations } \\
\text { of claws used for each statistical analysis }\end{array}$ \\
\hline \multicolumn{3}{|l|}{ Examination } \\
\hline $\mathrm{CT}^{1}$ & 600 & August 2011 to September 2016 \\
\hline $\mathrm{US}^{2}$ machine \#1 & 600 & August 2011 to September 2016 \\
\hline $\mathrm{US}^{2}$ machine $\# 2$ & $452^{3}$ & October 2012 to September 2016 \\
\hline Sole horn hardness & $320^{4}$ & August 2013 to September 2016 \\
\hline Macroscopic examination & $408^{5}$ & September 2012 to September $2016^{6}$ \\
\hline \multicolumn{3}{|l|}{ Statistical analyses } \\
\hline Analysis 1 , part $1-1$ & 408 & Macroscopic and CT examinations \\
\hline Analysis 1, part 1-2 & $\begin{array}{l}377,375 \text {, and } 364 \text { at points } \mathrm{S} 1, \mathrm{~S} 2, \text { and } \mathrm{S} 3 \text {, } \\
\text { respectively }\end{array}$ & Macroscopic examination and US machine \#1 \\
\hline Analysis 1, part 1-3 & $\begin{array}{l}552,548 \text {, and } 534 \text { at points S1, S2, and S3, } \\
\text { respectively }\end{array}$ & CT examination and US machine \#1 \\
\hline Analysis 2 , part $2-1$ & $452-1000$ & CT examination and US machines \#1, \#2 \\
\hline Analysis 2 , part $2-2$ & $\begin{array}{l}100,154 \text {, and } 177 \text { at points } \mathrm{S} 1, \mathrm{~S} 2 \text {, and } \mathrm{S} 3 \text {, } \\
\text { respectively, with probe } \mathrm{A}^{8} \\
35,40 \text {, and } 55 \text { at points } \mathrm{S} 1, \mathrm{~S} 2 \text {, and } \mathrm{S} 3 \text {, } \\
\text { respectively, with probe } \mathrm{B}^{8} \\
16,22 \text {, and } 32 \text { at points } \mathrm{S} 1, \mathrm{~S} 2 \text {, and S3, } \\
\text { respectively, with probe } \mathrm{C}^{8}\end{array}$ & $\begin{array}{l}\text { Complete US visualization not possible with probes } \mathrm{A}, \mathrm{B} \text {, } \\
\text { and } \mathrm{C}^{8} \text { in part } 2-1\end{array}$ \\
\hline Analysis 3 & 320 & Sole horn hardness, CT, and US machines \#1, \#2 \\
\hline Analysis 4 & 600 & CT and US machine \#1 \\
\hline \multicolumn{3}{|l|}{${ }^{1} \mathrm{CT}=$ computed tomography. } \\
\hline \multicolumn{3}{|l|}{${ }^{2} \mathrm{US}=$ ultrasound. } \\
\hline \multicolumn{3}{|c|}{$\begin{array}{l}{ }^{3} \text { Examination with US machine \#2 was added after the first examinations with CT and US machine \#1 for comparison of US visualization of } \\
\text { the sole structures with probes of } 2 \text { US machines. }\end{array}$} \\
\hline \multicolumn{3}{|c|}{$\begin{array}{l}{ }^{4} \text { Examination with a durometer was added after the first examination, for assessment of US visualization of sole structures as a function of sole } \\
\text { horn hardness. }\end{array}$} \\
\hline \multicolumn{3}{|c|}{${ }^{5}$ Macroscopic examination was added after the first examination for comparison of CT, US, and macroscopic measurements. } \\
\hline \multicolumn{3}{|c|}{$\begin{array}{l}{ }^{6} \text { During this period, macroscopic examinations were not done for } 18 \text { pairs of hind limbs because the specimens were soaked in hot water to } \\
\text { separate the horn capsules from the phalanges. }\end{array}$} \\
\hline \multicolumn{3}{|c|}{${ }^{7}$ Number of claws in which complete US visualization was possible with US machine \#1. } \\
\hline \multicolumn{3}{|c|}{${ }^{8}$ Probe $\mathrm{A}=\mathrm{US}$ machine $\# 1,6.5 \mathrm{MHz}$; probe $\mathrm{B}=\mathrm{US}$ machine $\# 1,5.0 \mathrm{MHz}$; probe $\mathrm{C}=\mathrm{US}$ machine $\# 2,5.0 \mathrm{MHz}$. } \\
\hline
\end{tabular}




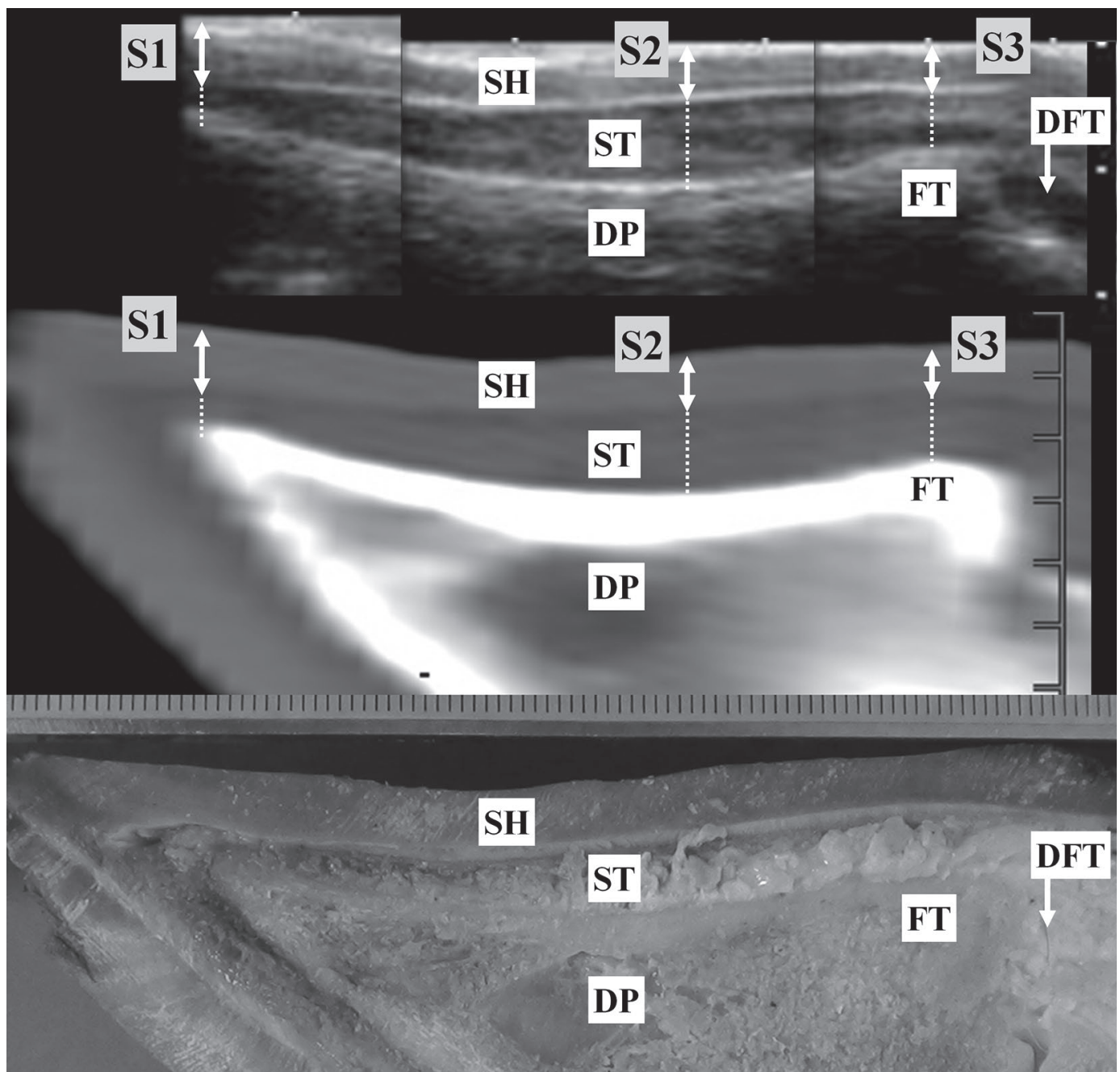

Figure 1. Images obtained by ultrasonographic and 2-dimensional computed tomographic (CT) images, and a photo of a postmortem specimen of a bovine claw in sagittal section, showing the measurement of sole horn thickness (double-headed arrows) at points S1 (region under the most apical margin of the distal phalanx), S2 (region under the deepest concavity of the ventral surface of the distal phalanx), and S3 [region under the flexor tuberosity (FT)]. On the ultrasonographic image, the ventral surface of the sole horn (SH), border between SH and soft-tissue layer (ST), and ventral surface of the distal phalanx (DP) are seen as 3 echogenic lines. DFT $=$ deep digital flexor tendon; scale $=10 \mathrm{~mm}$ between neighboring white dots on the ultrasound image, $5 \mathrm{~mm}$ between neighboring horizontal lines on the CT image, and millimeter scale on top of photo.

the weight-bearing surface at point S2 in the 160 inner and outer claws of 80 pairs of hind limbs according to Higuchi's method (Higuchi et al., 2005; Table 1). Three measurements per claw were made after US and CT, and the mean SHD value was calculated.

\section{Macroscopic Examinations}

Macroscopic examination was done from September 2012 to September 2016 (Table 1). A total of 102 pairs of hind limbs (204 inner and outer claws) were cut longitudinally from the midpoint of the toe area to the middle of the heel (= palmar/plantar $)$ region within a day of US and CT scanning. The SHT were obtained by manual measurement using an electric caliper at points $\mathrm{S} 1, \mathrm{~S} 2$, and $\mathrm{S} 3$.

\section{Statistical Analyses}

Analysis 1: Comparison of 3 Different Techniques for Measuring SHT: CT, US, and Macroscopic Examination. In part 1-1, correlations between the $\mathrm{CT}$ and macroscopic measurements were determined in the 408 claws that underwent both examinations (Table 1).

In part 1-2, correlations between the US and macroscopic measurements at points S1, S2, and S3 were determined in the 377,375 , and 364 claws, respectively, 
in which the SHT could be measured on the US images with probes A or B of US machine \#1 in the 408 claws that were examined macroscopically (Table 1 ).

In part 1-3, correlations between measurements obtained by $\mathrm{CT}$ and US at points $\mathrm{S} 1, \mathrm{~S} 2$, and $\mathrm{S} 3$ were determined in the 552,548 , and 534 claws, respectively, in which the SHT could be measured on the US images with probes A or B in US machine \#1 (Table 1).

In parts $1-1,1-2$, and $1-3$, the correlations were investigated using Pearson correlation coefficients at points S1, S2, and S3. Single linear regression analyses were done for correlations between the $\mathrm{CT}$ values (as explanatory variables) and US values (as response variables) of the SHT at points S1, S2, and S3. In the linear regression equation $[\mathrm{y}=$ (coefficient) $\times \mathrm{x}$ + (intercept)], the mean and standard error (SE) of the coefficient and intercept were calculated at points $\mathrm{S} 1, \mathrm{~S} 2$, and S3. In addition, the residual errors were calculated at points S1, S2, and S3.

Analysis 2: Comparison of 3 Probes and 2 US Machines for UVP, and Appearance of 3 Patterns of Poor US Visualization. In part 2-1, comparisons among UVP with 3 different probes of US machines \#1 and \#2 were determined in the 452 claws (of 113 pairs of hind limbs) that underwent US using all probes A, B, and C (Table 1). The claws, in which sole structures could or could not be represented by complete US views, were divided into ultrasonographic visualization (US-V) or ultrasonographic nonvisualization (US-NV) groups, respectively. One-way ANOVA was used for comparison between the SHT of US-V and US-NV groups for each of 3 probes, and among SHT obtained from 3 probes in the US-V group and the US-NV group at points S1, S2, and S3. The Scheffe test was used for post hoc analysis for ANOVA throughout the study. The UVP were statistically compared among the 3 probes (A, B, and $\mathrm{C}$ ) at each point (S1, S2, and S3) using the chi-squared test.

In part $2-2$, the US-NV group, poor US visualization could be divided into 3 patterns: pattern 1, nonvisualization of S-S line (NV-SS); pattern 2, nonvisualization of DP line (NV-DP); and pattern 3, nonvisualizatiom of both S-S and DP lines (NV-SS-DP). The chi-squared test was used to compare the proportions of the 3 patterns for each of the 3 probes, (A, B, and $\mathrm{C}$ ), at each point (S1, S2, and S3) in the US-NV group. Moreover, the mean (SE) of SHT in the regions with the 3 patterns in the US-NV group were calculated and statistically compared among data acquired with each probe (A, B, and $\mathrm{C}$ ), at each point (S1, S2, and S3) using ANOVA. In addition, the values were compared between NV-SS and NV-SS-DP using ANOVA; the number of claws with NV-DP $(\mathrm{n}=3)$ was too small for inclusion in the analyses.
Analysis 3: Effect of SHD on UVP with 3 Probes and 2 US Machines. To investigate the effect of SHD on US visualization, the 160 inner and outer claws of 80 pairs of hind limbs with measured values of SHD were included (Table 1). Analysis of variance was carried out to compare the SHD values among the inner, outer, and total claws. The UVP were calculated based on proportion of claws with complete US views at point S2 among 320 claws using probe A, B, and C. Values were statistically compared among the following groups: SHD $<40$ units (SHD40; $\mathrm{n}=110), 40$ to $<50$ units (SHD40-50; $\mathrm{n}=162$ ), and $\geq 50$ units (SHD50; $\mathrm{n}=48$ ); or probes $\mathrm{A}, \mathrm{B}$, and $\mathrm{C}$ in a total of 320 claws (80 pairs of hind limbs) using the chi-squared test. To investigate whether SHD-dependent US visualization was affected by an SHT $<10 \mathrm{~mm}$, of the 320 claws (with any SHT), the 160 claws from 61 pairs of hind limbs with an SHT $<10 \mathrm{~mm}$ were used for statistical analysis using the chi-squared test to compare UVP among the SHD40 $(\mathrm{n}=46)$, SHD40-50 $(\mathrm{n}=85)$, and SHD50 ( $\mathrm{n}=29)$ groups, and among probes A, B, and $\mathrm{C}$ in each SHD group.

Analysis 4: US Measurement Error of SHT and Total US Measurement Accuracy Within a $\pm 1 \mathrm{~mm}$ Range. In part 4-1, US measurement error of SHT was evaluated based on the difference between the values obtained by US and CT using each of 2 devices for the same claws, and the values measured on the US images were subtracted from the values measured on the $\mathrm{CT}$ images. The calculated value was referred to as the $\mathbf{C}-\mathbf{U}$ value, determined as the $\mathrm{CT}$ value minus the US value. A positive $\mathrm{C}-\mathrm{U}$ value signified US values smaller than $\mathrm{CT}$ values, and a negative $\mathrm{C}-\mathrm{U}$ value signified US values greater than $\mathrm{CT}$ values. A $\mathrm{C}-\mathrm{U}$ value of 0 signified equal US and CT values. The statistical correlation between the $\mathrm{C}-\mathrm{U}$ value and $\mathrm{SHT}$ on the $\mathrm{CT}$ images was investigated using Pearson correlation coefficients at points S1, S2, and S3. Correlation between the $\mathrm{C}-\mathrm{U}$ values (as response variables) and SHT (as explanatory variables) at point S1 was investigated using linear regression analysis. In addition, the mean and SE of the coefficient and intercept, and the residual error were calculated.

In part 4-2, the US measurements in the present study were defined as moderate when SHT measured using US were within a measurement error of $\pm 1 \mathrm{~mm}$ compared with those measured using CT (total US measurement accuracy within a $\pm 1 \mathrm{~mm}$ range). The values were assessed in claws with complete US views ( $\mathrm{n}=552,548$, and 534 at points $\mathrm{S} 1, \mathrm{~S} 2$, and S3, respectively). The claws were classified into 4 groups on the basis of SHT measured with CT as follows: $<5 \mathrm{~mm}$ (thin sole), 5 to $<7 \mathrm{~mm}$ (minimum adequacy), 7 to $<10$ $\mathrm{mm}$, and $\geq 10 \mathrm{~mm}$ (Toussaint Raven, 1989). Proportion 
of total US measurement accuracy within a $\pm 1 \mathrm{~mm}$ range among the 4 SHT groups, and that of the total values was assessed using the chi-squared test.

A $P$-value of $<0.05$ was considered to be significant.

\section{RESULTS}

\section{Parts 1-1, 1-2, and 1-3}

Significant and strong correlations were observed between CT and macroscopic measurements of SHT $(\mathrm{r}=$ $0.98,0.97$, and 0.96 ), and between US and macroscopic measurements of SHT $(r=0.91,0.90$, and 0.90) at points S1, S2, and S3, respectively. Measurements of SHT obtained by CT and US were strongly correlated at points $\mathrm{S} 1, \mathrm{~S} 2$, and $\mathrm{S} 3(\mathrm{r}=0.92,0.91$, and 0.92 , respectively). The linear equations describing the relationship between measurements of SHT obtained by CT and US (Table 2) and the regression lines (Figure 2) were similar for points S1, S2, and S3.

\section{Part 2-1}

Complete US views were obtained with probe A in $77.9,65.9$, and $60.8 \%$ of claws at points S1, S2, and S3, respectively (Table 3 ). The UVP were significantly lower than those with probe B $(92.3,91.2$, and $87.8 \%)$ or probe $\mathrm{C}(96.5,95.1$, and $92.9 \%)$ at points $\mathrm{S} 1, \mathrm{~S} 2$, and S3, respectively. Significant differences were observed between data acquired with probes $\mathrm{B}$ and $\mathrm{C}$ at all 3 points. In claws with complete US views, the average SHT with probe A was significantly lower than that with probes $\mathrm{B}$ or $\mathrm{C}$ at all 3 points. Figure 3 shows a decrease in echogenicity of the S-S line in association with thicker sole horns [in bovine claw (BC)-1, BC-2, and $\mathrm{BC}-3]$. The echogenicity of the S-S line decreased with probe $\mathrm{A}$ in $\mathrm{BC}-2$ and $\mathrm{BC}-3$ (SHT of 9.4 and 9.1 $\mathrm{mm}$, respectively) compared with BC-1 (SHT of 4.2 $\mathrm{mm}$ ), whereas the lines were clearly visualized on the US images of these 3 claws with probe C.

\section{Part 2-2}

In the US-NV groups (Table 1), the S-S line could not be seen in 25.0 to $53.1 \%$, and the S-S and DP lines could not be seen in 40.6 to $75.0 \%$ of the US images with the 3 probes at points S1-S3 (Table 4). The proportions of NV-SS-DP were significantly higher than the values of NV-SS acquired with probe $\mathrm{A}$ at all 3 points, and with probes $\mathrm{B}$ and $\mathrm{C}$ at point $\mathrm{S} 1$. The SHT in claws with NV-SS-DP were 13.12 to $14.28 \mathrm{~mm}$ for probe $\mathrm{A}$ and 17.82 to $19.16 \mathrm{~mm}$ for probe $\mathrm{B}$, which were significantly higher than those of NV-SS (mean,

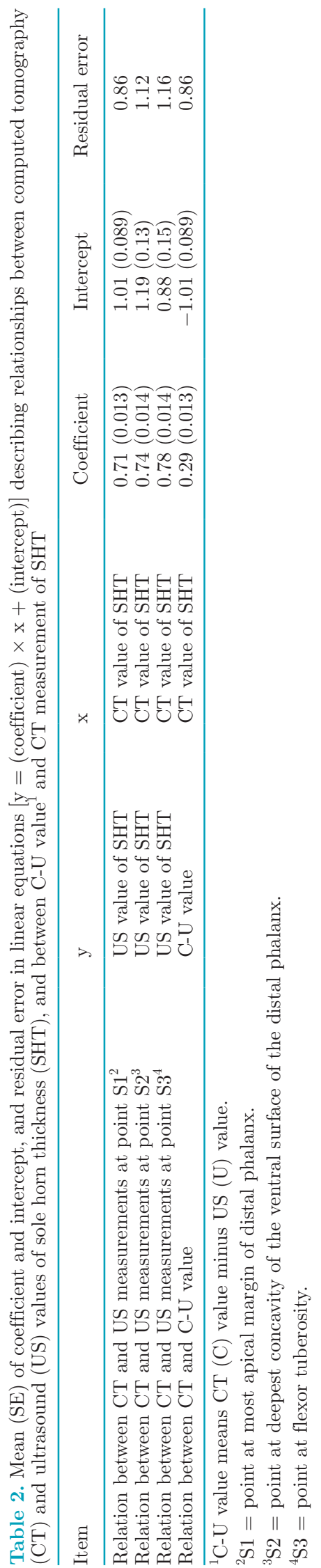


8.29 to $10.81 \mathrm{~mm}$ for probe $\mathrm{A}$ and 10.62 to $14.29 \mathrm{~mm}$ for probe B).

\section{Analysis 3}

In 160 inner and outer claws that were examined using a durometer, the mean (SE) SHD was 41.9 (0.51) units for the inner claw, 41.8 (0.57) units for the outer claw, and 41.8 (0.38) units for both claws, with no significant difference. The UVP with probe A were significantly lower than those with probes $\mathrm{B}$ or $\mathrm{C}$ (Table 5). With probe B, UVP in the SHD50 group were significantly lower than in the SHD40 and SHD40-50 groups. When probes A and B were used in 160 claws with an SHT $<10 \mathrm{~mm}$, UVP in the SHD50 group were significantly lower than those in the SHD40, and SHD40-50 groups (Table 5). The UVP obtained with probe A in 160 claws with an SHT $<10 \mathrm{~mm}$ were significantly lower than those obtained with probes B or C.
Part 4-1

Significant and strong correlations were observed between the C-U value and SHT at points S1, S2, and S3 $(\mathrm{r}=0.68,0.61$, and 0.57 , respectively). Linear equations describing the relationship between the $\mathrm{C}-\mathrm{U}$ value and SHT measured by CT (Table 2), and the graph (Figure 4) showed that increases in differences of SHT obtained by $\mathrm{CT}$ and US were associated with an increased SHT.

\section{Part 4-2}

The total US measurement accuracy within a $\pm 1 \mathrm{~mm}$ range at points $\mathrm{S} 1$ and $\mathrm{S} 2$ was significantly higher than that at point S3 (Table 6). The values in claws with an SHT $<5 \mathrm{~mm}$ were significantly higher than those with an SHT of 5 to $<7 \mathrm{~mm}, 7$ to $<10 \mathrm{~mm}, \geq 10 \mathrm{~mm}$, and all claws combined.

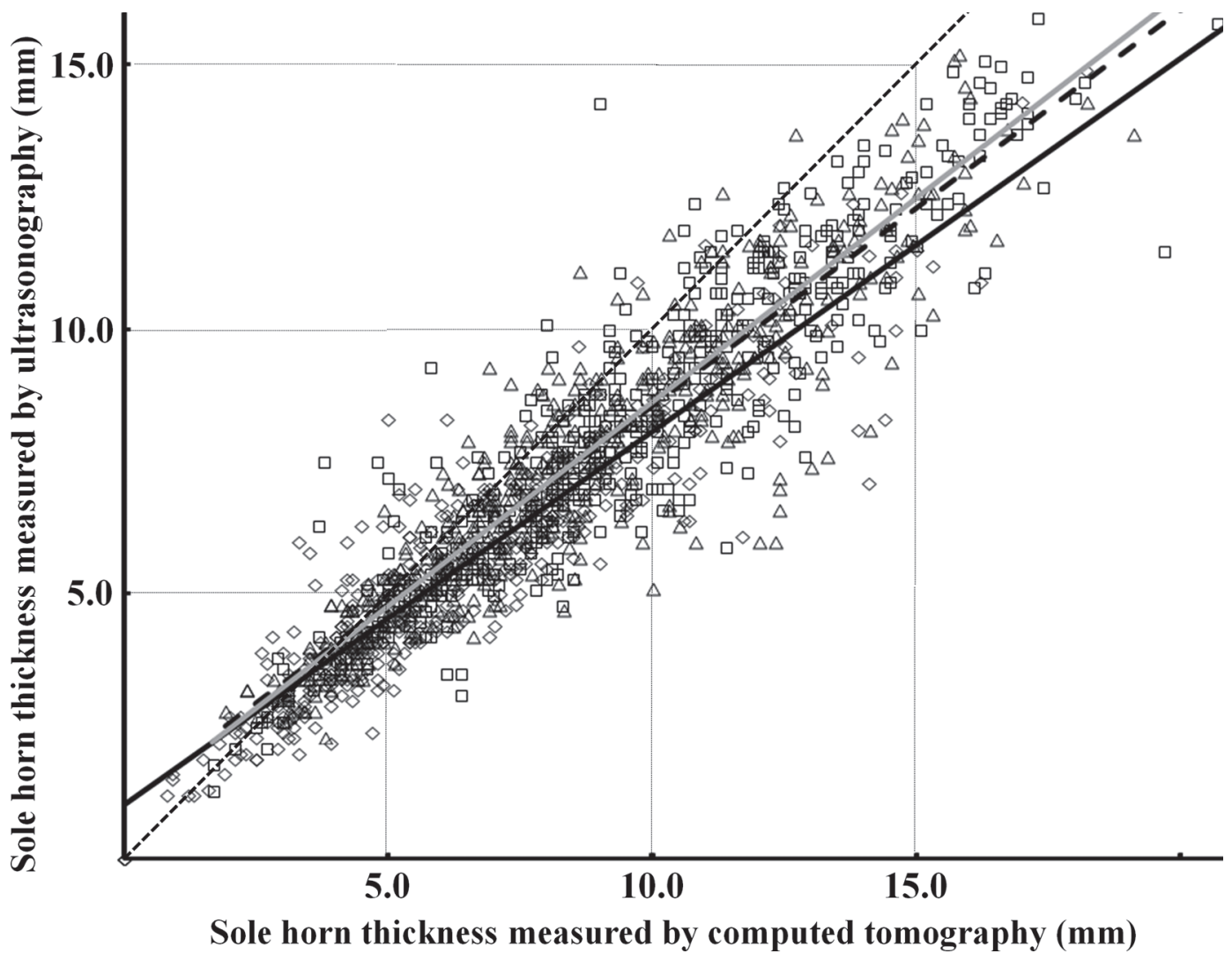

Figure 2. Correlation between computed tomographic and ultrasonographic measurements of sole horn thickness (SHT) at points S1 (region under the most apical margin of the distal phalanx, solid black line), S2 (region under the deepest concavity of the ventral surface of the distal phalanx, broken black line), and S3 (region under the flexor tuberosity, solid gray line). Open diamonds, triangles, and squares represent the values at points S1, S2, and S3, respectively. The thin dashed line marks the identity line that represents agreement between ultrasonographic and computed tomographic measurements. The course of the solid and broken black lines and the solid gray line relative to the identity line shows that ultrasonography underestimates the SHT compared with computed tomography. 


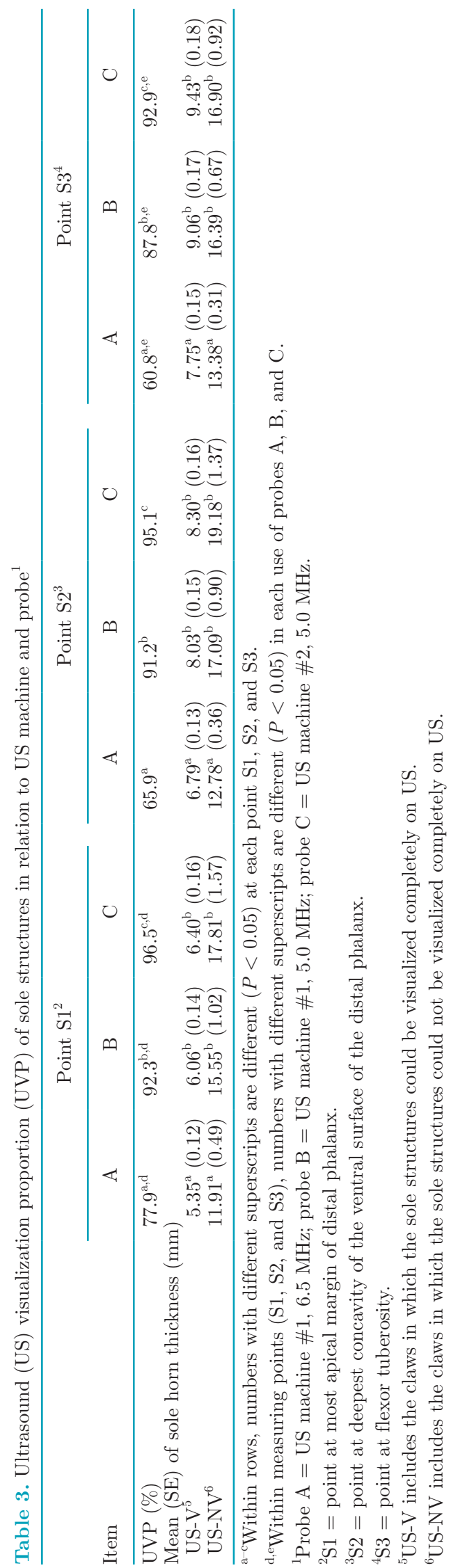

\section{DISCUSSION}

In the present study, analysis 1 yielded strong correlations, which was similar to Kofler's data, but contrasted Laven's data, in which lower values were reported (Kofler et al., 1999; Laven et al., 2010). The US values were underestimated compared with the macroscopic values in claws with an SHT $>5 \mathrm{~mm}$, which was in agreement with Kofler's data (Kofler et al., 1999). This finding was also supported by our data, which showed that the US values were underestimated compared with those of CT.

In part 2-1, the UVP was lower with the $6.5-\mathrm{MHz}$ probe than with either of the $5.0-\mathrm{MHz}$ probes, which indicated that a lower US wave frequency is associated with better visualization of sole structure at deeper sites. A frequency of $6.5-\mathrm{MHz}$ may not be sufficient for US wave transmission through the sole horns. Characteristic image patterns related to poor US visualization included nonvisualization of the S-S line, which is considered a landmark (Kofler et al., 1999). In analysis 2-2, nonvisualization of the S-S line was also seen in 94 to $100 \%$ of claws, in which sole structures could not be represented by complete US views (addition of both NV-SS and NV-SS-DP), and was a common sign of poor US visualization at any of the points S1, S2, and S3 and with any of the probes A, B, and C. In Table 4, averages of SHT related to NV-SS were close to $10 \mathrm{~mm}$ with probe A and ranged from 10 to $15 \mathrm{~mm}$ with probes B and C. Nonvisualization of the DP line as well as the S-S line (NV-SS-DP) tended to be associated with an SHT of $>13 \mathrm{~mm}$ with probe A, and an SHT of $>17 \mathrm{~mm}$ with probes B and C. The effect of attenuation of the US waves through thick sole horn may be associated more with nonvisualization of the S-S line than the DP line because the echogenicity of the S-S line is usually less than that of the DP line. Moreover, differences were seen among the various target points. With probe A, the UVP at the apex of the sole structures (point S1) was higher than that at the central and caudal sole structures (points S2 and S3). This finding was likely associated with uneven or curved weight-bearing surfaces at the central and caudal sites, preventing stable contact with the probe.

Hardness of the sole horns is another factor associated with poor US visualization. In analysis 3, claws with a greater SHD had a lower UVP with both of the $5.0-\mathrm{MHz}$ probes (probes $\mathrm{B}$ and $\mathrm{C}$ ), although the UVP with the $6.5-\mathrm{MHz}$ probe (probe A) was approximately $50 \%$ regardless of SHD, Use of probe B in $>90 \%$ of claws with an SHD $<50$ units enabled US visualization compared with a low UVP in claws with an SHD > 50 units. Thus, SHD of an 50 units may be the threshold for US visualization. In claws with an SHT $<10 \mathrm{~mm}$, 

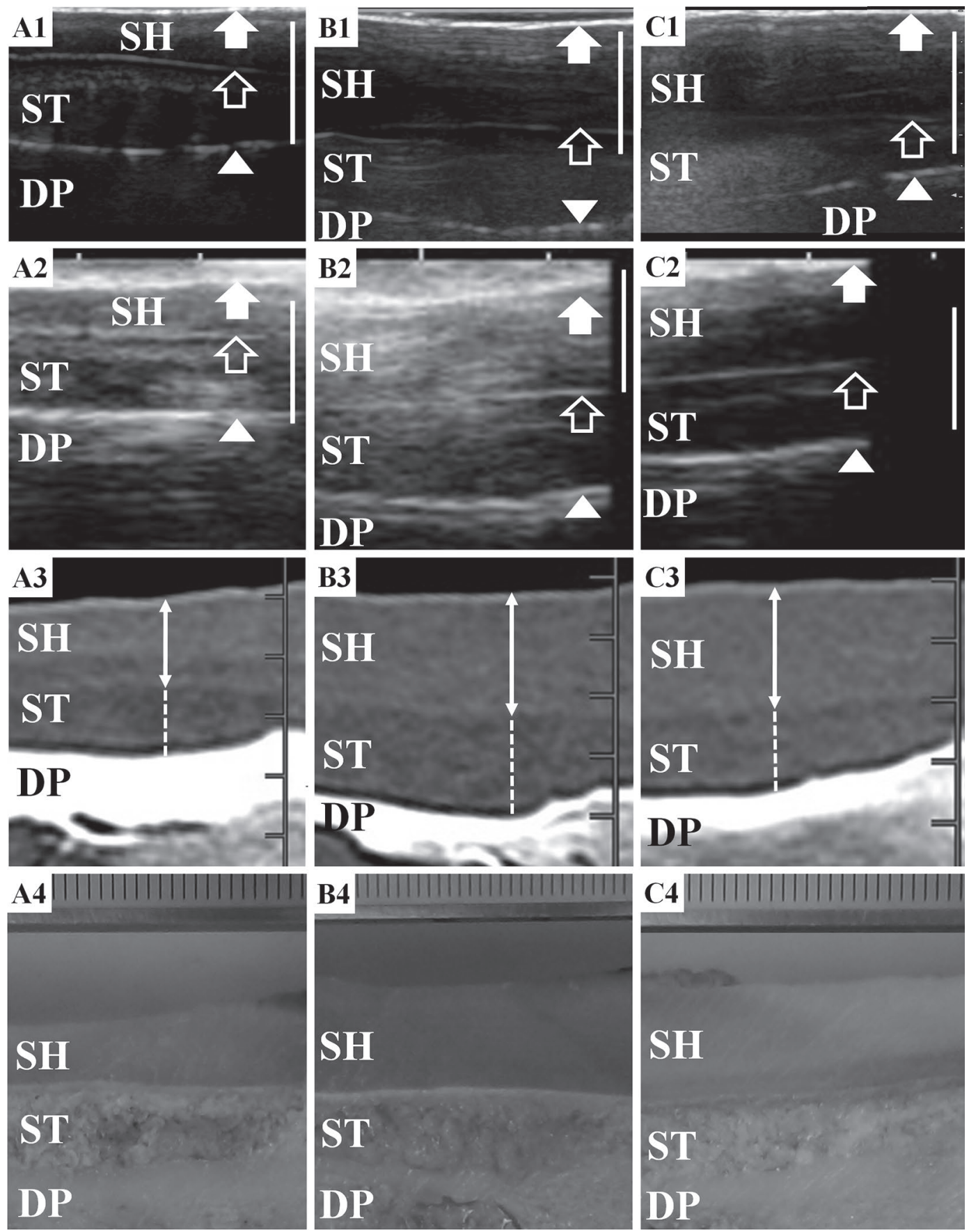

Figure 3. Ultrasonographic images obtained with probe A (A1, B1, and $\mathrm{C} 1$ ) and probe $\mathrm{C}$ (A2, B2, and C2), 2-dimensional computed tomographic images (A3, B3, and C3), and macroscopic images (A4, B4, and C4) of the sole structures close to the deepest concavity of the ventral surface of the distal phalanx. (A1 to A4): The echogenic line (S-S line) between the sole horn (SH) and soft-tissue layers (ST) is clearly imaged with both probes A and $\mathrm{C}$ in bovine claw (BC)-1; sole horn thickness (SHT) is $4.2 \mathrm{~mm}$ and sole horn hardness (SHD) is 42 units. (B1 to B4): Echogenicity of the S-S line is weak compared with that of BC-1 with probe A in BC-2; SHT is 9.4 mm and SHD is 33 units. (C1 to C4): Echogenicity of the S-S line is slightly lower than that in BC-2 with probe A in BC-3; SHT is $9.1 \mathrm{~mm}$ and SHD is 48 units, but is similar to the images obtained in BC-2 and BC-3 with probe C. DP = distal phalanx; arrowhead = echogenic line of the ventral surface of DP; double-headed arrow $=$ SHT; open arrow $=$ S-S line; solid arrow $=$ echogenic line of ventral surface of SH. Scale as in Figure 1. 
TSUKA ET AL.

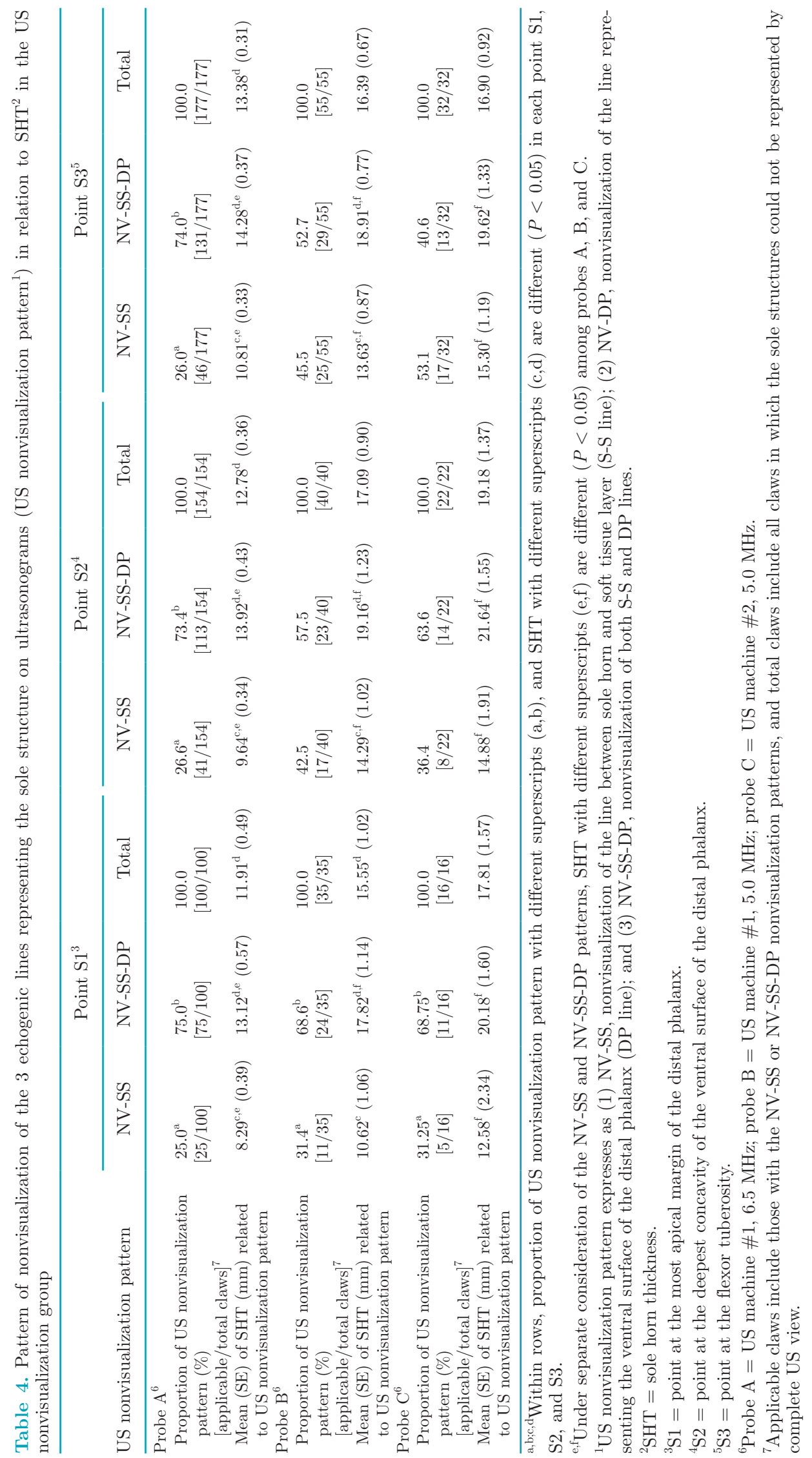


Table 5. Effect of sole horn hardness on ultrasonographic (US) visualization proportion

\begin{tabular}{|c|c|c|c|c|}
\hline \multirow[b]{2}{*}{ Item } & \multicolumn{4}{|c|}{ Sole horn hardness } \\
\hline & $<40$ units & 40 to $<50$ units & $\geq 50$ units & Total \\
\hline \multicolumn{5}{|c|}{$\begin{array}{l}\text { Claws with sole horn } \\
\text { thickness }<10 \mathrm{~mm}(\mathrm{n}=160)\end{array}$} \\
\hline Probe $A^{1}$ & $91.3^{\mathrm{a}, \mathrm{d}}$ & $85.9^{\mathrm{a}, \mathrm{d}}$ & $69.0^{\mathrm{a}, \mathrm{e}}$ & $84.4^{\mathrm{a}, \mathrm{d}}$ \\
\hline Probe $B^{1}$ & $100.0^{\mathrm{b}, \mathrm{d}}$ & $100.0^{\mathrm{b}, \mathrm{d}}$ & $89.7^{\mathrm{e}}$ & $98.1^{\mathrm{b}, \mathrm{d}}$ \\
\hline Probe $\mathrm{C}^{1}$ & 97.8 & $100.0^{\mathrm{b}}$ & $96.6^{\mathrm{b}}$ & $98.8^{\mathrm{b}}$ \\
\hline \multicolumn{5}{|c|}{ All claws $(\mathrm{n}=320)$} \\
\hline Probe $A^{1}$ & $53.6^{\mathrm{a}}$ & $58.6^{\mathrm{a}}$ & $50.0^{\mathrm{a}}$ & $55.6^{\mathrm{a}}$ \\
\hline Probe $\mathrm{B}^{1}$ & $93.7^{\mathrm{b}, \mathrm{d}}$ & $91.4^{\mathrm{b}, \mathrm{d}}$ & $77.1^{\mathrm{b}, \mathrm{e}}$ & $86.9^{\mathrm{b}}$ \\
\hline Probe $\mathrm{C}^{1}$ & $89.1^{\mathrm{b}}$ & $95.1^{\mathrm{b}}$ & $91.7^{\mathrm{c}}$ & $91.6^{\mathrm{b}}$ \\
\hline
\end{tabular}

US visualization of sole structures was related to the SHD at the sole surface and the wave frequency. With probe A, a decrease in the UVP was significantly associated with an increased in the SHD (by comparison among 3 SHD groups). The SHD-dependent decrease in UVP was not evident with probes $\mathrm{B}$ and $\mathrm{C}$, despite significant differences among the SHD groups with probe B. Comparison of the findings of probes $\mathrm{A}$ and $\mathrm{C}$ (Figure 3) showed that SHD did not affect US visualization when a $5.0-\mathrm{MHz}$ probe was used, provided that the SHT was $<10 \mathrm{~mm}$.

Hard sole horn is a characteristic associated with healthy claws in cattle (Vermunt and Greenough, 1995). Most normal bovine claws were shown to have an SHD > 40 units (Baggott et al., 1988; Tranter et al., 1993; Borderas et al., 2004; Higuchi et al., 2005), and some had an SHD >50 units (Manson, 1986; Kremer et al., 2004). Hardness of the sole horns is dependent on the relative amounts of various tissue components including water, proteins, collagens, and keratins (Baggott et al., 1988; Hinterhofer et al., 2007; Winkler and Margerison, 2012). In claws with hard sole horns, the low moisture content is associated with a relative abundance of skeletal components, including keratins and collagens (Vermunt and Greenough, 1995; van Amstel et al., 2004). The increasing in the attenuation of US waves is paralleled by a decrease in the water and an increase in the protein content (particularly keratins and collagens) of body tissues (Amin, 1989; Barcaui et al., 2016). Thus, US visualization may be difficult in healthy bovine claws because of the high SHD, and this indicates good claw health. On the other hand, US of bovine claws may be warranted for determination of thin soles and other diseases such as laminitis because many of these claws have a lower SHD than normal claws (Manson, 1986; Baggott et al., 1988; Tranter et al., 1993; van Amstel et al., 2004; Higuchi et al., 2005).
In this study, the data obtained using US were not compared with measurements of the moisture content in the sole horns. The SHD values were considered reliable in one report (Higuchi et al., 2005), but the accuracy of SHD measurements using our method may have been slightly inferior compared with Borderas' method, which involved serial applications of a springloaded probe at defined locations on the claw (Borderas et al., 2004). Alternatively, the mechanical properties of bovine sole horns can be evaluated using other analytic techniques, such as sole elasticity (using the modulus of elasticity and puncture resistance testing), tensile strength, and stiffness (Hinterhofer et al., 2007; Winkler and Margerison, 2012). Therefore, these different quantitative methods should be used to determine why US visualization of sole structures is often difficult.

The present data suggested that compared with CT, the extent of underestimation of SHT using US tended to increase with an increase in SHT. In claws with a $\mathrm{SHT}>5 \mathrm{~mm}$, the US values tended to be smaller (mean, $1.2 \mathrm{~mm}$ ) than the macroscopic values (Kofler et al., 1999). The reason for underestimation of SHT when using US is not known, but may be associated with degree of attenuation and distortion of US wave through the sole horns with different tissue components (Nyland et al., 1995). Ultrasound scanner can measure the time between pulse emission and echo registration, and convert the measured time into a distance on the assumption that the speed of US through tissues is constant (Nyland et al., 1995; Fabiszewska et al., 2017). Variation of the tissue components (such as water, collagens, and keratins) may influence the constant passing of US wave through the sole horns (Nyland et al., 1995; Fabiszewska et al., 2017). In addition, for claws with thicker sole horns, there was an unintentional tendency to move the probe in a craniocaudal or axial/ abaxial direction at each defined point (S1, S2, and S3) 


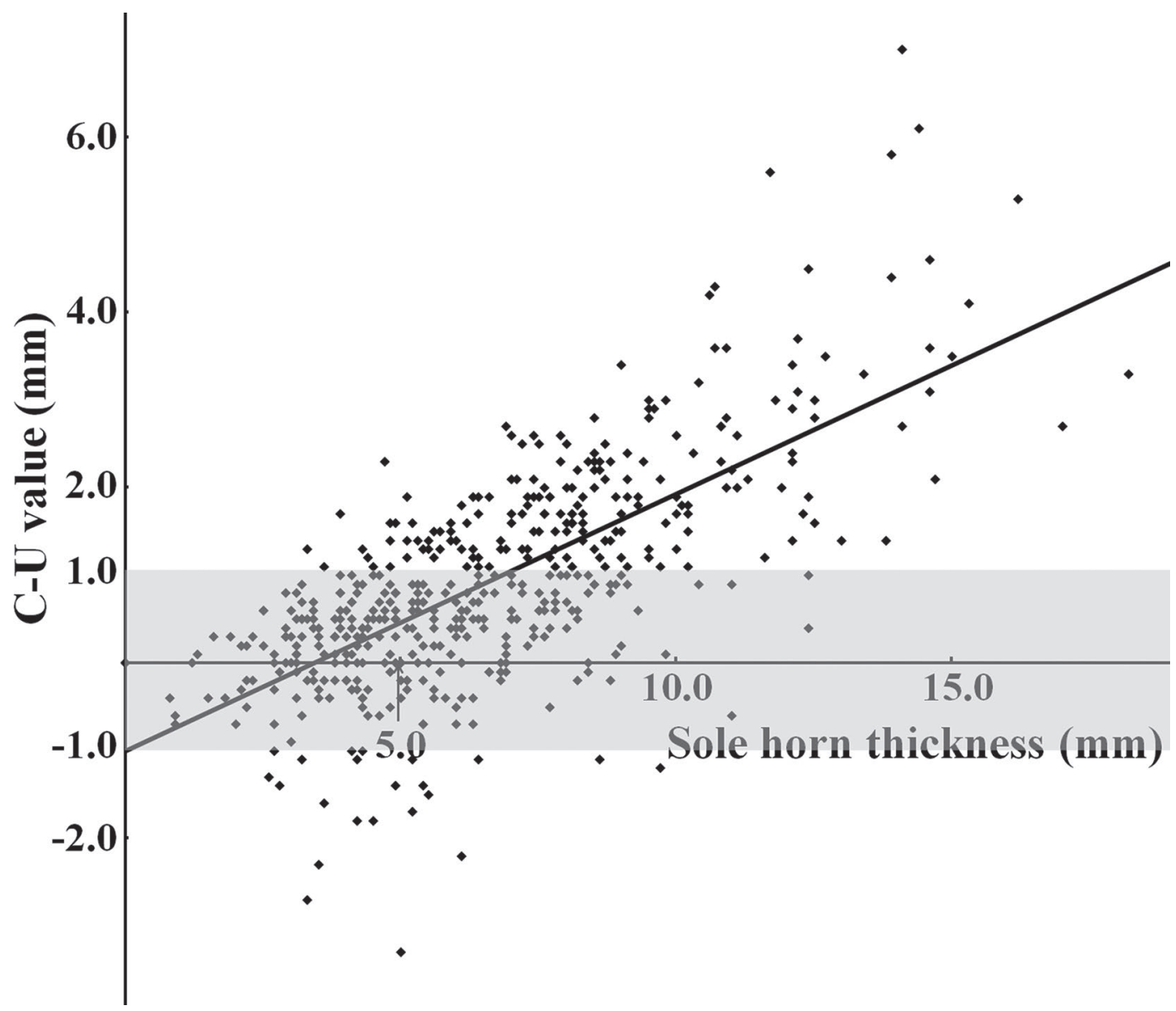

Figure 4. Correlation between the C-U value, defined as the computed tomographic (CT) measurement minus the ultrasound (US) measurement of sole horn thickness (SHT), and SHT measured on CT images at point S1 (region under the most apical margin of the distal phalanx). The linear equation is $\mathrm{y}=0.29 \mathrm{x}-1.01$, where y represents the $\mathrm{C}-\mathrm{U}$ value and $\mathrm{x}$ represents the SHT. The gray zone represents the C-U values within $\pm 1 \mathrm{~mm}$. Of note, the majority of data for claws with an SHT $<5 \mathrm{~mm}$ are located within the gray zone.

Table 6. Effects of sole horn thickness on total measurement accuracy within a $\pm 1 \mathrm{~mm}$ range with probes A or B in ultrasound (US) machine

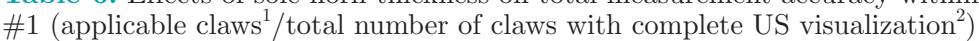

Sole horn thickness

\begin{tabular}{|c|c|c|c|c|c|}
\hline Item & $<5 \mathrm{~mm}$ & 5 to $<7 \mathrm{~mm}$ & 7 to $<10 \mathrm{~mm}$ & $\geq 10 \mathrm{~mm}$ & Total \\
\hline $\begin{array}{l}\text { Point S1 } \\
\text { Point } \mathrm{S}^{4} \\
\text { Point S3 }\end{array}$ & $\begin{array}{l}84.9(169 / 199)^{\mathrm{a}} \\
90.0(72 / 80)^{\mathrm{a}} \\
91.3(42 / 46)^{\mathrm{a}}\end{array}$ & $\begin{array}{l}67.6(94 / 139)^{\mathrm{b}} \\
71.9(82 / 114)^{\mathrm{b}} \\
66.7(56 / 84)^{\mathrm{b}}\end{array}$ & $\begin{array}{l}28.9(43 / 149)^{\mathrm{c}, \mathrm{f}} \\
51.2(88 / 172)^{\mathrm{c}, \mathrm{g}} \\
40.9(70 / 171)^{\mathrm{c}, \mathrm{g}}\end{array}$ & $\begin{array}{r}6.2(4 / 65)^{\mathrm{d}, \mathrm{f}} \\
19.2(35 / 182)^{\mathrm{d}, \mathrm{g}} \\
19.7(46 / 233)^{\mathrm{d}, \mathrm{g}}\end{array}$ & $\begin{array}{l}56.2(310 / 552)^{\mathrm{e}, \mathrm{f}} \\
50.5(277 / 548)^{\mathrm{c}, \mathrm{f}} \\
40.1(214 / 534)^{\mathrm{c}, \mathrm{g}}\end{array}$ \\
\hline
\end{tabular}

${ }^{\mathrm{a}-\mathrm{e}}$ Within rows, numbers with different superscripts are different $(P<0.05)$.

${ }^{\mathrm{f}, \mathrm{g}}$ Within columns, numbers with different superscripts are different $(P<0.05)$.

${ }^{1}$ Applicable claws include the claws in which US values of sole horn thickness within a measurement accuracy of \pm 1 mm compared with the computed tomographic values.

${ }^{2}$ Complete US visualization means that 3 echogenic lines representing the ventral surface of the sole horn, the border between the sole horn and soft-tissue layer, and the ventral surface of the distal phalanx are visualized on US.

${ }^{3} \mathrm{~S} 1$ = point at the most apical margin of the distal phalanx.

${ }^{4} \mathrm{~S} 2=$ point at the deepest concavity of the ventral surface of the distal phalanx.

${ }^{5} \mathrm{~S} 3=$ point at the flexor tuberosity. 
because this improved visualization of the 3 echogenic lines (Kofler et al., 1999). This accidental deviation from the defined measuring points may have produced SHT measurements that were smaller than those at the defined locations.

Computed tomography is considered to be a reliable method of measuring SHT in sagittal claw sections (Kofler et al., 1999; Tsuka et al., 2014). The variability in sole structures such as irregular and uneven sole surfaces may result in small measurement errors in SHT when determining SHT by CT, but could be a common source of error in macroscopic measurements using sagittal sections of claws (Kofler et al., 1999; Laven et al., 2010). Moreover, it was difficult to determine whether the points measured with US corresponded with those on the CT images in each claw. The US target sites on the weight-bearing surface of claws should be labeled with a metallic marker to allow their identification on the CT images.

The $\mathrm{C}-\mathrm{U}$ values, calculated as the difference between the values obtained by $\mathrm{CT}$ and US, increased with increasing SHT measured with CT. In part 4-2, approximately $90 \%$ of claws with an SHT $<5 \mathrm{~mm}$ had a measurement accuracy of within a $\pm 1 \mathrm{~mm}$ range using US. This indicates that US is useful for diagnosing thin soles in cows. Approximately $70 \%$ of claws with an SHT of 5 to $7 \mathrm{~mm}$, which is considered to be the minimum thickness for adequate horn condition, had a measurement accuracy within a $\pm 1 \mathrm{~mm}$ range using US (Toussaint Raven, 1989; Laven et al., 2012). Based on the linear equation for the correlation between US and CT values, the US SHT measurements were estimated at 4.6 to $6.0 \mathrm{~mm}$ at $\mathrm{S} 1,4.9$ to $6.4 \mathrm{~mm}$ at $\mathrm{S} 2$, and 4.8 to $6.3 \mathrm{~mm}$ at $\mathrm{S} 3$ for corresponding values of 5 to $7 \mathrm{~mm}$ measured on CT images. However, underestimation of the SHT via US would not likely increase the risk of creating thin soles during hoof trimming. The US evaluation of claws with an SHT $\geq 10 \mathrm{~mm}$ tended to result in a larger underestimation of the SHT, and therefore cannot be recommended. In the present report, a measurement error (C-U value) within $\pm 1 \mathrm{~mm}$ was considered to be moderate for the US measurements, but may still be clinically significant considering that SHT usually is in the millimeter range. It is currently not possible to define an acceptable value for the error in US measurements of SHT in the bovine claws.

In the present report, the UVP was higher when measured with US machine \#2, which was a portable machine, than with machine \#1. Portable US machines are needed for measurement of SHT in the field. Poor imaging quality and resolution were problems faced in the past due to the lower capacity of older portable US machines (Kofler et al., 1999; Laven et al., 2012).
However, technological advances in portable machines are expected to overcome these shortfalls (Laven et al., 2012). Potential uses for US include evaluation of claws before and after hoof trimming and the diagnosis and treatment of claw diseases, especially thin soles.

\section{CONCLUSIONS}

The results of the present study indicated that poor US visualization of sole structures in the bovine claw was associated with a higher US frequency $(6.5-\mathrm{MHz}$ probe vs. $5.0-\mathrm{MHz}$ probe), an $\mathrm{SHT} \geq 10 \mathrm{~mm}$, and an SHD $\geq 50$ units. Three echogenic lines representing different sole structures (line at the ventral surface of the sole horn, S-S line, and DP line) could be visualized in the majority of claws with a $5.0-\mathrm{MHz}$ probe regardless of SHD, provided that the SHT was $<10 \mathrm{~mm}$. Compared with CT, US allowed the measurement of SHT within a $\pm 1 \mathrm{~mm}$ range in approximately $90 \%$ of the claws with an SHT $<5 \mathrm{~mm}$, which was defined as a thin sole. This suggests that US is a useful diagnostic tool in cows with thin soles, and will allow precautions to be taken when trimming feet.

\section{ACKNOWLEDGMENTS}

We thank Hideya Inoue at the Shiga Prefectural Institute of Public Health (Shiga, Japan) for advice on statistical techniques at the time of the preparation of this report.

\section{REFERENCES}

Amin, V. R. 1989. Ultrasonic attenuation estimation for tissue characterization. PhD Thesis. Department of Biomedical Engineering, Iowa State University, Ames.

Baggott, D. G., K. J. Bunch, and K. R. Gill. 1988. Variations in some inorganic components and physical properties of claw kelatin associated with claw disease in the British Friesian cow. Br. Vet. J. 144:534-542.

Barcaui, E. O., A. C. Carvalho, F. P. Lopes, J. Piñeiro-Maceira, and C. B. Barcaui. 2016. High frequency ultrasound with color Doppler in dermatology. An. Bras. Dermatol. 91:262-273.

Borderas, T. F., B. Pawluczuk, A. M. de Passillé, and J. Rushen. 2004. Claw hardness of dairy cows: Relationship to water content and claw lesions. J. Dairy Sci. 87:2085-2093.

Fabiszewska, E., K. Pasicz, I. Grabska, W. Skrzyński, W. ŚlusarczykKacprzyk, and W. Bulski. 2017. Evaluation of imaging parameters of ultrasound scanners: Baseline for future testing. Pol. J. Radiol. $82: 773-782$

Higuchi, H., M. Nakamura, A. Kuwano, M. Kasamatsu, and H. Nagahata. 2005. Quantities and types of ceramides and their relationships to physical properties of the horn covering the claws of clinically normal cows and cows with subclinical laminitis. Can. J. Vet. Res. 69:155-158.

Hinterhofer, C., V. Apprich, J. C. Ferguson, and C. Stanek. 2007. Modulus of elasticity and dry-matter content of bovine claw horn affected by the changes of chronic laminitis. Vet. J. 174:605-609. 
Kofler, J., P. Kübber, and W. Henninger. 1999. Ultrasonographic imaging and thickness measurement of the sole horn and the underlying soft tissue layer in bovine claws. Vet. J. 157:322-331.

Kremer, P., S. Nuske, A. Scholz, and M. Forster. 2004. Influence of different floor conditions on claw development, metabolism and milk yield in dairy cows housed in stalls with free cow traffic. Pages 210-212 in Proc. XIII Int. Symp. on Lameness in Ruminants. Maribor, Slovenia.

Laven, L. J., J. K. Margerison, and R. A. Laven. 2010. Measurement of sole thickness and the distance to distal phalanx using a portable ultrasound machine. Proc. N. Z. Soc. Anim. Prod. 70:240-242.

Laven, L. J., J. K. Margerison, and R. A. Laven. 2012. Validation of a portable ultrasound machine for estimating sole thickness in dairy cattle in New Zealand. N. Z. Vet. J. 60:123-128.

Manson, F. J. 1986. A study of lameness in dairy cows with reference to nutrition and hoof shape. PhD Thesis, Univ. Glasgow, Scotland.

Nyland, T. G., J. S. Mattoon, and E. R. Wisner. 1995. Physical principles, instrumentation, and safety of diagnostic ultrasound. Pages 3-18 in Veterinary Diagnostic Ultrasound. T. G. Nyland, and J. S. Mattoon, ed. Saunders Co., Philadelphia, PA.

Shearer, J. K., and S. R. van Amstel. 2001. Functional and corrective claw trimming. Vet. Clin. North Am. Food Anim. Pract. 17:53-72.
Toussaint Raven, E. 1989. Structure and function. Pages 24-26 in Cattle Foot Care and Claw Trimming. E. Toussaint Raven, ed. Farming Press, Ipswitch, UK.

Tranter, W. P., R. S. Morris, I. R. Dohho, and N. B. Williamson. 1993. A case-control study of lameness in dairy cows. Prev. Vet. Med. 15:191-203.

Tsuka, T., Y. Murahata, K. Azuma, T. Osaki, N. Ito, Y. Okamoto, and T. Imagawa. 2014. Quantitative evaluation of the relationship between dorsal wall length, sole thickness, and rotation of the distal phalanx in the bovine claw using computed tomography. J. Dairy Sci. 97:6271-6285.

van Amstel, S. R., F. L. Palin, B. W. Rorhbach, and J. K. Shearer. 2003. Ultrasound measurement of sole horn thickness in trimmed claws of dairy cows. J. Am. Vet. Med. Assoc. 223:492-494.

van Amstel, S. R., J. K. Shearer, and F. L. Palin. 2004. Moisture content, thickness, and lesions of sole horn associated with thin soles in dairy cattle. J. Dairy Sci. 87:757-763.

Vermunt, J. J., and P. R. Greenough. 1995. Structural characteristics of the bovine claw: Horn growth and wear, horn hardness and claw conformation. Br. Vet. J. 151:157-180.

Winkler, B., and J. K. Margerison. 2012. Mechanical properties of the bovine claw horn during lactation. J. Dairy Sci. 95:1714-1728. 